\title{
Knowledge and Awareness About Risk Factors of Cervical Cancer, Its Screening and Vaccination Among the Women Attending Chittagong Medical College Hospital
}

\author{
Fahmida Shirin Papri \\ Zubaida Khanam ${ }^{2}$ \\ Fahmida Islam \\ Md Monjurul Hakim ${ }^{4}$
}

'Department of Gynaecology \& Obstetrics Chittagong Medical College Chittagong,Bangladesh.

${ }^{2}$ Department of Community Medicine Chittagong Medical College

Chittagong, Bangladesh

${ }^{3}$ Department of Obstetrics \& Gynaecology Chandanaish Health Complex

Chandanaish, Chittagong, Bangladesh.

${ }^{4}$ Department of Anatomy Chittagong Medical College Chittagong, Bangladesh.
*Correspondence to:

\author{
Dr. Fahmida Shirin Papri \\ Assistant Professor \\ Department of Gynaecology \& Obstetrics \\ Chittagong Medical College \\ Chittagong, Bangladesh \\ Mobile : +88 01711948384 \\ Email : shirinfahmida44@yahoo.com
}

www.banglajol.info/index.php/CMOSHMCJ

\begin{abstract}
Cervical cancer is one of the leading causes of morbidity and mortality amongst the gynaecological cancer in Bangladesh.This study was carried out to assess the knowledge of cervical cancer, awareness of the women towards the cervical cancer screening program and its vaccination in Bangladesh. A cross- sectional interview based study was conducted using a self administered questionnaire between January 1,2013 and June 31, 2013 on 508 respondents. Convenience sampling was applied among the women attending at Gynae Out Patient Department (GOPD) of Chittagong Medical College Hospital for VIA (Visual Inspection with Acetic Acid) test. Of the 508 respondents only $211(41.54 \%)$ told that they had idea about cervical cancer, while only $114(22.44 \%)$ knew that VIA is the screening test for cervical cancer.A total of $390(76.77 \%)$ respondents did not know any cause of cervical cancer.Most of the respondents (80\%) came for VIA due to doctor's advice.After doing VIA among 229 respondents, 149 (65.07\%) told that they had been counseled for the next follow - up by the health professionals and $118(51.52 \%)$ were ready for routine periodic screening.Majority $(85.88 \%)$ of the respondents were absolutely ignorant about the vaccine of cervical cancer. Age and marital status did not influence their knowledge but the level of education and occupation was found to positively influence their knowledge of cervical cancer and their acceptance of the screening test.This study highlights that majority of women in Bangladesh are not adequately equipped with knowledge concerning cervical cancer. Adequate health information and counseling on cervical cancer and regular screening test need to be emphasized in our country.
\end{abstract}

Key words: Knowledge and awareness; Risk factor; Cervical cancer; Screening program; Vaccination.

\section{INTRODUCTION}

Cervical cancer is the most common form of cancer in developing countries and the second most common form of cancer in the world as a whole. Almost $80 \%$ of cervical cancer occur in the developing countries. Bangladesh and India have annual incidence of cervical cancer of 11956 and 12595 respectively. According to the World Health Organization (WHO) statistics, incidence of cervical cancer cases in Bangladesh has been estimated at 167 per 1,00,000 populations and 6,582 women die every year in the country for this cancer ${ }^{1}$.

The problem of cervical cancer in Bangladesh is particularly acute because of poverty, early age marriage, multiple marriages, high parity and illiteracy. In developing countries, women's knowledge about risk factors of cervical cancer is very limited. However it is considered one of the most preventable cancers ${ }^{2}$. Of all the screening tests available for cervical cancer, Visual Inspection with Acetic Acid (VIA) is the on going screening program in Bangladesh. VIA meets the criteria of a good screening test. It involves visually examining the cervix with naked eye after the application of $5 \%$ acetic acid ${ }^{3}$. It is claimed that majority of the cervical cancer(theoretically upto $90 \%$ ) could be prevented if all women were offered screening programs ${ }^{4}$. 
Epidemiological studies have identified that infection with oncogenic types of Human Papilloma Virus (HPV) is a necessary cause of cervical cancer ${ }^{5}$ HPV vaccines have been developed and vaccination, if done before the person becomes sexually active, would offer great protection. HPV vaccine like 'Cervarix' offer protection against HPV-16 and-18 and are given in three doses over a six month period ${ }^{6}$. So this study was carried out to assess the knowledge and awareness about risk factors of cervical cancer, its screening and vaccination among the women came for VIA test (Visual Inspection with Acetic Acid) an screening procedure of cervical cancer in Gynae Out Patint Department of Chittagong Medical College Hospital, a tertiary hospital in Bangladesh.

\section{MATERIALS \& METHODS}

A cross sectional, interview-based study was conducted in the Gynae Out Patient Department of Chittagong Medical College among the women who came here for VIA test. Women come here for VIA or Pap smear test being referred by doctors or from Inpatient departments (Admitted in the gynae ward) and also with self interest. An average of about 10 patients attend here to do VIA test. The study was conducted from January to June, 2013. A total of 1018 women undergone VIA test in this period. But among them, interview was taken from only 508 respondents.Because women who did not give consent were excluded from the study.

Data collection tools and analysis

Questionnaire containing both open and closed type of questions was designed based on the study objectives, taking help from the previous literature and studies available on the topic.Face to face interview was taken by two investigators to avoid interobserver error. Analysis was done using on Statistical Package for Social Science (SPSS version 18). Percentage were calculated for all the variables. Relevant tables and graphs were computed.

\section{RESULTS}

The age range of the participants was between 18 and 60 years. Majority $(43.90 \%)$ of the participants were within the age range of 26 to 35 years. Among all the subjects, the majority $(77.16 \%)$ were housewives. The occupation of the husbands were mainly private job and business. The subjects hailing from urban area in $57.48 \%$ cases and $38.58 \%$ respondents had income within Tk 5000-10,000.Of all the respondents $188(37.01 \%)$ participants were educated up to secondary level and $21.26 \%$ were illiterate.

Age at first marriage of $400(78.74 \%)$ participants was within 15 to 18 years. The parity distribution revealed $50.19 \%$ attendees had 3 to 4 conception. A total of 238 $(46.85 \%)$ respondents used hormonal contraceptives and $28.35 \%$ used no contraceptive methods (Table 1).

A total of $76.77 \%$ of the sample said that they 'don't know' the causes of cervical cancer and thus they were not asked any question related to the etiology (Table 2). More than five risk factors were reported from the participants which included early age at first marriage \& coitus $(5.71 \%)$, multiple partners and promiscuous behavior $(5.11 \%)$, poor hygiene $(3.75 \%)$, multiparty $(3.95 \%)$ and infection $(5.31 \%)$. About $80 \%$ of the respondents were referred by the registered doctors to do the screening test. Only $20 \%$ came with self interest.
Table 2 also shows that 22. 25\% respondents had the VIA test before, while only $22.44 \%$ of the respondents knew that VIA or Pap smear is a screening test for cervical cancer. Majority $(77.56 \%)$ of the attendees knew that it was a test for examination of the whole uterus.

Among 229 respondents in this study, 65.07\% were given instruction for next follow up by the health care provider and $53.71 \%$ were ready for routine periodic screening if given the opportunity but $48.47 \%$ were still not sure. In total only 12 out of 85 respondents who were asked about vaccine against cervical cancer were aware of the vaccine of cervical cancer (Table 3). Rest of them told that they did not hear about the vaccine. The knowledge was significantly higher among the women with high education level, were employed and those who came from urban area $(\mathrm{p}<0.0001)$ (Table 4).

Table 1: Demographic characteristics of the women participating in the study

$\begin{array}{lrr}\text { Characteristics } & \text { No. } & \text { Percentage } \\ \text { Age (Years) } & & \\ 18-25 & 79 & 15.55 \% \\ 26-35 & 223 & 43.90 \% \\ 36-45 & 171 & 33.66 \% \\ 46-55 & 35 & 6.89 \% \\ \text { Occupation of the Respondents } & \\ \text { Housewife } & 392 & 77.16 \% \\ \text { Office job } & 34 & 6.79 \% \\ \text { Garment worker } & 43 & 8.46 \% \\ \text { House maid } & 13 & 2.56 \% \\ \text { Day labour } & 8 & 1.57 \% \\ \text { Others } & 18 & 3.55 \%\end{array}$

\section{Residence of the Respondents}

Urban 292

Rural 216

$57.48 \%$

$42.52 \%$

Family Income (Taka)

$<5000$

$5000-10,000$

\section{1}

$10,000-20,000$

196

$>20,000$

156

$38.58 \%$

$38.58 \%$

$30.71 \%$

Education level

Illiterate $\quad 108$

Literate 56

Primary 156

Secondary and above $\quad 188$

$16.73 \%$

Age at First Marriage (years)

15-19 400

$>20 \quad 108$

$21.26 \%$

$11.02 \%$

$30.71 \%$

$37.01 \%$

Number of Concoption

$1-2 \quad 130$

$3-4 \quad 255$

$>4 \quad 123$

$78.74 \%$

$21.26 \%$

Use of Contraception

Hormonal 238

$\mathrm{Cu} \mathrm{T} 27$

Barrier 71

BLTL 28

None $\quad 144$

$25.60 \%$

$50.19 \%$

$24.21 \%$

$46.85 \%$

$5.31 \%$

$13.98 \%$

$5.51 \%$

$28.35 \%$ 
Table 2 : Knowledge and awareness of the women about risk factors of cervical cancer and its screening

$\begin{array}{lrr}\text { Knowledge/Awareness } & \text { No. } & \text { \% } \\ \text { Don't know } & 390 & 76.77 \% \\ \text { Early age of marriage } & 29 & 5.71 \\ \text { Multiparity } & 15 & 3.95 \\ \text { Poor hygiene } & 19 & 3.75 \% \\ \text { Infection } & 27 & 5.31 \\ \text { Multiple partners and } & 26 & 5.11 \\ \text { promiscuous behaviour } & & \\ \text { Reason for coming for screening } & 406 & \\ \text { Doctor's advice } & 102 & \\ \text { Self } & & \\ \text { Knowledge regarding VIA } & 394 & 77.56 \\ \text { Examination of uterus } & 114 & 22.44 \\ \text { Cancer screening test } & & \\ \text { Previous screening for cervical cancer } & \\ \text { Yes } & 113 & 22.25 \\ \text { No } & 395 & 77.75 \\ \text { Have you been told anything about next follow up } \mathbf{?} \text { N=229 } \\ \text { Yes } & 149 & 65.07 \\ \text { NO } & 80 & 34.03\end{array}$

Would you come to do this screening test again for follow up?

$\begin{array}{lll}\text { Yes } & 123 & 53.71 \\ & 106 & 46.29\end{array}$

Table 3 : Awareness about vaccination of cervical cancer Do you know there is a vaccine which is given to prevent cervical cancer? $\mathrm{N}=85$

\begin{tabular}{lll} 
Yes & 12 & 14.12 \\
No & 73 & 85.88 \\
\hline
\end{tabular}

Table 4 : Knowledge of the women according to socio demographic characteristics

\begin{tabular}{|c|c|c|c|}
\hline Characteristics & Number & Having knowledge & P-value \\
\hline \multicolumn{4}{|l|}{ Education level } \\
\hline Upto primary level & 320 & 36 & $\chi^{2}=67.768$ \\
\hline Secondary and above & 188 & 82 & $\mathrm{p}<0.001$ \\
\hline \multicolumn{4}{|l|}{ Residence } \\
\hline Urban & 292 & 96 & $\chi^{2}=34.588$ \\
\hline Rural & 216 & 22 & $\mathrm{p}<0.0001$ \\
\hline \multicolumn{4}{|l|}{ Employment status } \\
\hline Unemployed & 392 & 27 & $\chi^{2}=253.047$ \\
\hline Employed & 116 & 91 & $\mathrm{p}<0.0001$ \\
\hline
\end{tabular}

\section{DISCUSSION}

This study provides baseline information for planning a cervical cancer prevention programme in Bangladesh.In this study, the knowledge and awareness among the women about the risk factors of cervical cancer, its screening and vaccination were identified. The results showed a deficiency in women's knowledge about the risk factors of cervical cancer which revealed that about $76.77 \%$ of the respondents had no knowledge about the cause of cervical cancer. Such findings have been reported by a number of previous studies in Arab communites.In the presnt study, the poor level of knowledge was related to illiteracy and unemployment. This relation between education and knowledge has been reported in previous studies in Arab and Hispanic women ${ }^{7,8}$. In this study, knowledge of women about VIA test was also evaluated.Only $22.44 \%$ of the participants knew that it is a screening test for cervical cancer. A study conducted in tertiary hospital in Karachi, Pakistan evaluated the knowledge of interns and nurses about Pap smear, showed only $40 \%$ of the respondents were aware that Pap smear is the screening test for cervical cancer ${ }^{9}$. This result can explain why most of the cervical cancer in our country present in advanced stage.

Among 229 respondents, $65.07 \%$ were given instruction for next follow up by the health care providers and most $(53.71 \%)$ of them were eager for routine screening while participants who did not get any instruction were not awere for next follow up screening. This result reveals that health care providers have a very important role to play in getting people interested in the screening program.

The results showed that very few of the respondents were aware of the vaccine against Human Papilloma Virus (HPV) which is an important cause of cervical cancer.Prevention of cervical cancer can be divided into primary prevention which includes vaccine and secondary prevention which includes screening. Prevention of HPV infection is very essential in prevention of cervical cancer. Many studies have been done worldwide recently on the knowledge, awareness and practice of HPV vaccine.The studies reported better knowledge in developed countries like USA, Belgium and Australia, but in developing countries like Thailand, Turkey and China had poor information about HPV vaccine ${ }^{9}$.

\section{CONCLUSION}

This study highlights inadequate knowledge about cervical cancer and its screening amongst the women of Bangladesh. In this country, cervical cancer is the commonest genital tract cancer in female. Despite its public health importance, there are no effective prevention programs in Bangladesh and hence the risk of the disease and death from cervical cancer remains largely uncontrolled.Health education, promotion of screening program and raising awareness about its vaccination is the most cost effective approach in reducing the incidence of cervical cancer in resource crunched society like Bangladesh.Cervical cancer control activities should be included in the existing 'reproductive and child health program.Only through proper health education of the people and also the health care workers, burden of cervical cancer can be reduced.

\section{DISCLOSURE}

All the authors declared no competing interest. 


\section{REFERENCES}

1. Khatun SF, Homaira R, Khatun S, Sharmin F et al. Performance of VIA (Visual Inspection With Acetic Acid) and Colposcopic Biopsy as a Method of Screening in Detecting Preinvasion and Early Cancerous Lesion of the Cervix. Medicine Today.2011;23(1):13-14.

2. Pontin J et al. Strategies for Global control of cervical cancer. International Journal of Cancer. 1995;60(1):1-26.

3. Sankaranarayanan R, Budukh A and Rajkumar R. Effective screening programs for cervical cancer in low and middle incoming developing countries. Bull World Health Organ. 2001;79:954-962

4. Al Meer F.M, Aseel M.T,Al Khalaf J. Knowledge, attitude and practices regarding cervical cancer and screening among women visitng primary health in Qatar.Eastern Mediterranean Health Journal.2011;17(11):855-860.

5. IARC Working Group. Human Papilloma Viruses. IARC Monograph on the Evaluation of Carcinogenic Risks to Humans.Lyon: International Agency for Research on Cancer. 1995;65.

6. Senapathy JG, Umadevi P, Kannika PS et al.The Present Scenario of Cervical Cancer Control and HPV Epidemiology in India: an outline.Asian Pacific J Cancer Prev. 1998;12:1107-1115.

7. Al Sairafi M, Mohamed FA.Knowledge, attitudes and practice related to cervical cancer screening among Kuwaiti women. Medical Principles and Practice. 2009;18(1):35-42.

8. Ramirez AG et al.Hispanic women's breast and cervical cancer knowledge, attitude and screening behaviors. American Journal of Health Promotion.2000;14(5):292-300.

9. Ali SF, Ayub S,Manzoor NF,Azim S, Afif M, Uddin N et al.Knowledge and Awareness about Cervical Cancer and its Prevention amongst Interns and Nursing Staff in Tertiary Care Hospital in Karachi, Pakistan.PLOS One. 2010;5(6):11059. 